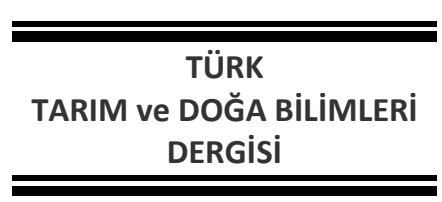

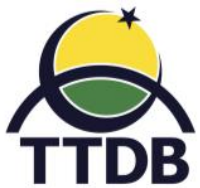

www.dergipark.gov.tr/turkjans

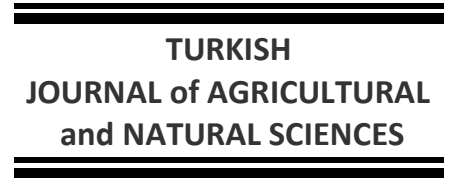

Araştırma Makalesi

\title{
Karadeniz'de Karaya Vuran ve Kazara Yakalanan Yunuslar (Cetacea) Hakkında: Ölüm Nedenleri, Beslenme Özellikleri ve Gebelik Durumu
}

\author{
Sabri BILGIN ${ }^{1 *}$, Hatice ONAY², Ozay KÖSE² ${ }^{2}$ Tuncay YEŞiLÇiçEK ${ }^{2}$ \\ ${ }^{1}$ Sinop Üniversitesi Su Ürünleri Fakültesi, 57000 Sinop, Türkiye \\ ${ }^{2}$ Recep Tayyip Erdoğan Üniversitesi Su Ürünleri Fakültesi, 53000 Rize, Türkiye \\ *Sorumlu yazar: sbrbilgin@hotmail.com
}

Geliş Tarihi: 17.04.2018

Düzeltme Geliş Tarihi: 20.09.2018

Kabul Tarihi: 02.10 .2018

Özet

Bu çalışma, Kalkan dip uzatma solungaç ağlarıyla yapılan avcılıkta Karadeniz'de yaşayan iki yunus türünün (Mutur, Phocoena phocoena ve Tırtak, Delphinus delphis) karaya vuran miktarı ve ölüm nedenleri ile bazı üreme ve beslenme özelliklerinin belirlenmesi için Rize kıyı şeridinde yürütülmüştür. Dip uzatma kalkan ağlarıyla kazara yakalanan yunuslar (71 Mutur ve 4 Tırtak) ağlara dolanarak boğulmuş ve yunuslar kalkan ağlarına zarar verememiştir. Karaya vuran yunusların (6 Mutur ve 4 Tırtak) \%60'ı P. phocoena, \%40'ı ise $D$. delphis türüdür. Karaya vuran yunusların muhtemel ölüm sebeplerinin avcılık sırasında ağlara kazara takılıp boğulmaları ve deniz kirliliği olduğu belirlenmiştir. P. phocoena türü Haziran ve Temmuz aylarında çiftleşmeye başlamakta, Mayıs'tan sonra ise doğum gerçekleşmektedir. Çalışmada 52 Mutur ve 6 Tırtak midesi incelenmiştir. Hem sayısal varlık hem de bulunuş frekansı açısından Mutur başlıca Hamsi (\% N = 86; \%FO = \%63), Mezgit (\% $\mathrm{N}=12 ; \% \mathrm{FO}=\% 25)$ ve istavrit (\% $\mathrm{N}=2 ; \% \mathrm{FO}=\% 11)$ balıkları ile Tırtak ise Hamsi $(\% \mathrm{~N}=8, \% \mathrm{FO}=43)$ ve istavrit (\%N = $5 \% \mathrm{FO}=43$ ) balıklarıyla beslenmiştir.

Anahtar kelimeler: Cetacea, kazara yakalanma, balıkçılık, Karadeniz.

\section{About Stranding and Accidentally Caught Cetaceans in the Black Sea: Death Reasons, Feeding Characteristics and Pregnancy Status}

\begin{abstract}
This study was carried out to determine stranding levels, dead reasons and some reproduction features and diet of the Black Sea' cetacean species (harbour porpoise, Phocoena phocoena and common dolphin, Delphinus delphis) Rize coast in the Black Sea. By caught cetaceans ( 71 harbour porpoise and 4 common dolphins) were drowned entangled in the nets and they did not damage the turbot nets. Stranding levels of the Black Sea' cetaceans (6 harbour porpoise and 4 common dolphins) were $60 \%$. phocoena and $40 \% D$. delphis. Probable causes of death of stranding cetaceans were determined as asphyxia and marine pollutions. Mating of $P$. phocoena begins between June and July and calving takes after May. A total of 52 harbour porpoise and 6 common dolphin stomach examined for diet analyzes. Harbour porpoises feed mainly anchovy ( $\mathrm{N}=86 \%$; $\mathrm{FO}=$ $63 \%)$, whiting $(\mathrm{N}=12 \%$; $\mathrm{FO}=25 \%)$ and horse mackerel $(\mathrm{N}=2 \%$; $\mathrm{FO}=11 \%)$, and also common dolphin feed mainly anchovy $(\mathrm{N}=8 \%, \mathrm{FO}=43 \%)$ and horse mackerel $(\mathrm{N}=5 \%$; $\mathrm{FO}=43 \%)$.
\end{abstract}

Key words: Cetacea, by catch, fisheries, Black Sea.

Giriş

Günümüzde dünya genelinde denizlerde, Cetacea takımında, 13 aileye ait 78 deniz memelisi türü dağılım göstermektedir (Jefferson ve ark., 1993). Türkiye denizlerinde ise 10 Cetacea türü bilinmektedir (Öztürk ve ark., 2004). Karadeniz'de Cetacean takımına ait liman yunusu ya da Mutur Phocoena phocoena (Linnaeus, 1758), Afalina, Tursiops truncatus (Montagu, 1821) ve Tirtak Delphinus delphis (Linnaeus, 1758) olmak üzere üç 
tür yaşamaktadır (Zaitsev ve Mamaev, 1997; Öztürk ve ark., 2004).

Dünyada yıllık yaklaşık 308.000 yunus ve balina balık avcılığı sırasında balıkçı ağlarıyla kazara yakalanmaktadır (Read ve ark., 2004). Özellikle $T$. truncatus ve $P$. phocoena yunus türleri avcılık sırasında en çok kazara yakalanan türlerdir (Read ve ark., 2004). Sadece $P$. phocoena türünün kazara yakalanma miktarı kuzey Avrupa denizlerinde 10.000 civarındadır (Franse, 2005). Karadeniz'de yunus avcılığı 1966 yılında USSR, Romanya ve Bulgaristan'da ve 1983 yılında ise Türkiye'de yasaklanmıştır. Ayrıca, Karadeniz'de bulunan $P$. phocoena relicta Abel, 1905, D. delphis ponticus Barabasch-Nikiforov, 1935 ve T. truncatus ponticus Barabasch, 1940 yunus türleri, Monako'da Mart 2006 tarihinde IUCN/ACCOMBAS tarafından düzenlenen çalıştay da nesli tehlike altında (EN) kategorisine dahil edilmiş ve bu türler Karadeniz'de yaşayan üç alt yunus türü olduğu şeklinde değerlendirilmiştir (ACCOBAMS, 2007).

Yunusların avcılığının yasak olmasına rağmen, yapılan öngörülere göre Türkiye'de balıkçılık nedeniyle ölen sadece $P$. phocoena sayısı yılda 3000 civarında, T. truncatus sayısı ise 10001500 civarındadır (Öztürk ve ark., 1999).

Karadeniz'de yaşayan yunusların balıkçılıkla etkileşiminin önemli bir boyutu avlanmayan, ekonomik olarak değerlendirilmeyen ve besin zincirinin en üstünde yer alan yunusların balık stokları üzerine av baskısı etkisidir. Bu durum zaman zaman medyaya yansımakta ve balıkçılar tarafından "yunusların balık stoklarını yiyerek tüketildikleri ve yunusların avlanmaları gerektiği" şeklinde gündem oluşturabilmektedir.

Bu çalışma, Kalkan solungaç ağlarıyla yapılan balık avcılığında, Karadeniz'de yaşayan iki yunus türünün ( $P$. phocoena ve $D$. delphis) karaya vuran miktarı ve ölüm nedenlerinin belirlenmesi ile karaya vuran ve kalkan ağlarıyla kazara yakalanan yunuslar üzerinden gebelik durumları ve beslenme özelliklerinin tespit edilmesi amacıyla Rize kıyı şeridinde yürütülmüştür.

\section{Materyal ve Yöntem}

Bu araştırma Karadeniz' de Rize kıyı şeridinde Ardeşen ve İyidere sahillerinde gerçekleştirilmiştir (Şekil 1). Mart 2010 ve Eylül 2011 tarihleri arasında aylık olarak 19 ay süreyle kalkan dip uzatma solungaç ağlarıyla avcılık yapılarak veriler alınmıştır. Kalkan avcılığının yasak olduğu Mayıs ve Haziran aylarında örnekleme yapabilmek için Gıda, Tarım ve
Hayvancılık Bakanlığından gerekli yasal izin alınmıştır. Ayrıca yunuslar üzerinde çalışmak için Recep Tayyip Erdoğan Üniversitesi Hayvan Deneyleri Etik Kurulundan gerekli yasal izin alınmıştır. Çalışma süresince 72 avcılık operasyonu İyidere mevkiinde, 64 avcılık operasyonu ise Ardeşen mevkiinde 10 - 50 m derinlikler arasında gerçekleştirilmiş olup toplamda 136 avcılık operasyonu yapılmıştır.

Araştırmada $320 \mathrm{~mm}$ ağ gözü açıklığında, 7 $\mathrm{mm}$ ağ gözü derinliğinde, $210 \mathrm{~d} / 2 \times 3$ numara ipten yapılmış ve donam faktörü $E=0.36$ olacak şekilde donatılmış ağlar kullanılmıştır (Şekil 2). $72 \mathrm{~m}$ uzunluğunda (yaklaşık 40 kulaç) kalkan solungaç ağlarından 5 - 7 adet (0.36- 0.504 km uzunluğunda) birbirine eklenerek bir avcılık operasyonu için ağ kombinasyonu oluşturulmuştur. Bu ağlarla aylık avcılık denemeleri yapılmıştır. Bir avcılık operasyonu için kullanılan ağların toplam uzunluğu 0.36 ve $1.8 \mathrm{~km}$ (ortalama $0.60 \pm 0.026 \mathrm{~km}$ ) arasında değişmiştir. Ağlar deniz şartlarına bağlı olarak 4 ve 18 gün arasında (ortalama 7.64 \pm 0.219 gün) suya bırakılmıştır. Bazı avcılık operasyonları farklı uzunlukta ancak aynı teknik özellikteki ağlarla aynı günde farklı derinlikteki bölgelerde gerçekleştirilmiştir.

Karadeniz'de bulunan üç yunus türü tespiti FAO tarafından hazırlanan ilgili literatürde (Jefferson ve ark., 1993; Öztürk ve ark., 2004) belirtildiği gibi sistematik özelliklerden yararlanılarak yapılmıştır. Karaya vuran yunusların tamamının (6 Mutur ve 4 Tırtak) ve kazaraen yakalanan 71 Mutur'dan 46'sının, 4 Tırtak bireyinden ise 2'sinin mide içerikleri incelenmiştir. Mide içeriği incelenen yunusların nekropsi işlemleri ve boy ölçümleri Su Ürünleri Fakültesine ait balıkçı barınağında yapılmıştır. Mide analizleri ise Su Ürünleri Fakültesi laboratuarında yapılmıştır. Yunuslar üzerinde yara durumu, ağ izi gibi emareler dikkate alınarak nekropsileri yapılmış (Duignan ve ark., 2003) ve muhtemel ölüm nedenleri saptanmıştır.

Mide içeriklerinin değerlendirilmesinde Hyslop, (1980); Dolar ve ark., (2003); Ringelstein ve ark., (2006); Pusineri ve ark., (2007)'den yararlanılmıştır. $\mathrm{Bu}$ amaçla arazi çalışmaları sırasında karınları açılan yunusların mideleri alınarak buzluklara konulmuş ve laboratuvara getirilmiştir. Alınan mideler ileriki zamanlarda incelenmek üzere $-20^{\circ} \mathrm{C}^{\prime}$ de derin dondurucuda saklanmıştır. 


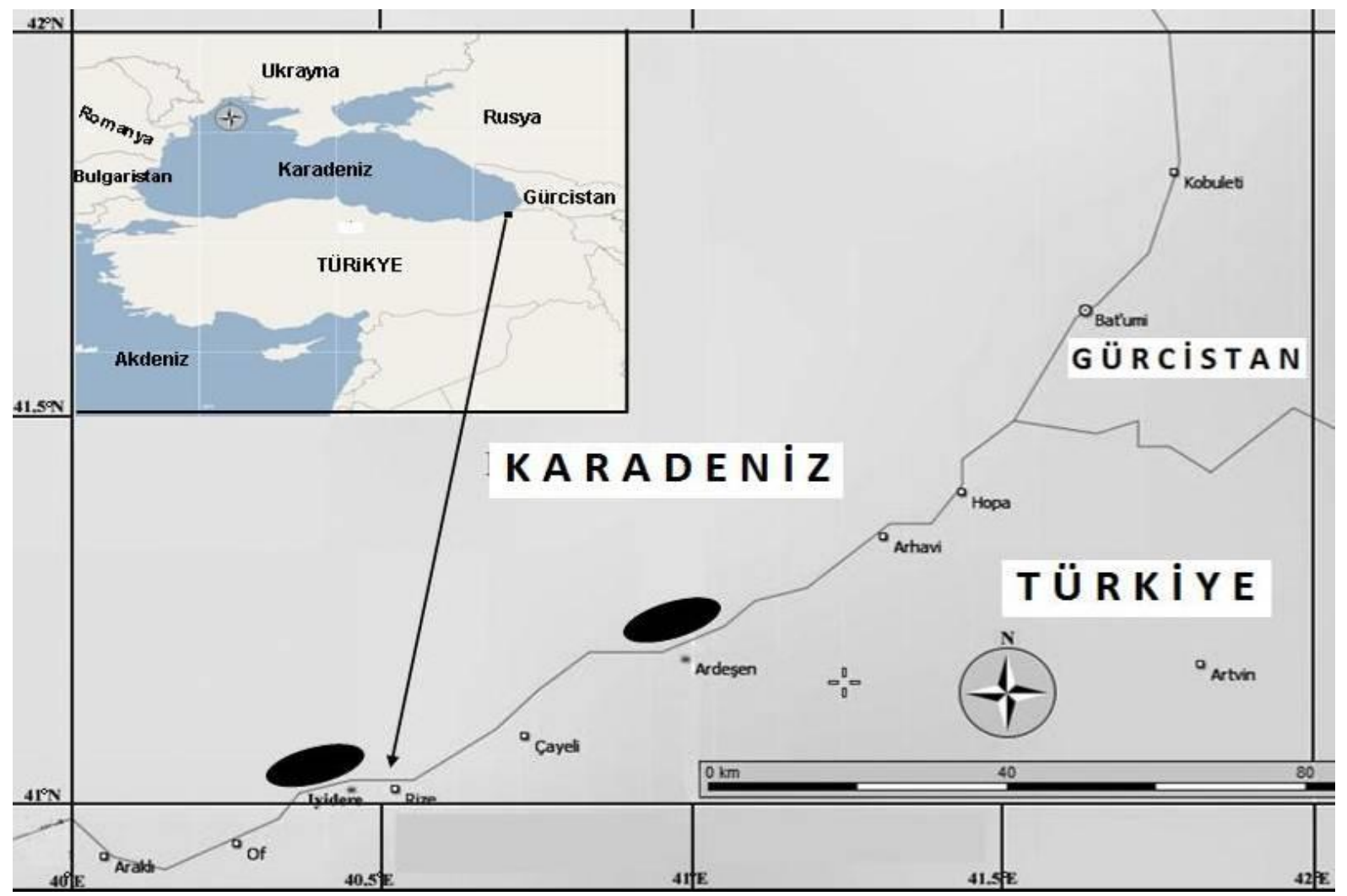

Şekil 1. Rize sahil şeridinde denemelerinin gerçekleştirildiği araştırma istasyonları.

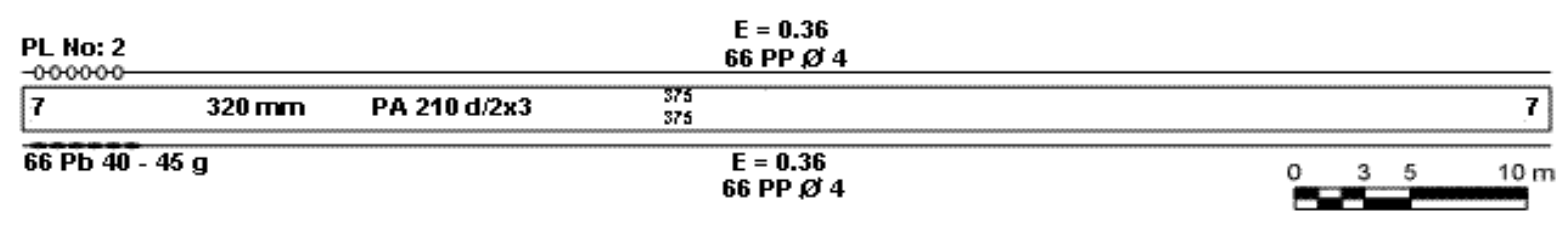

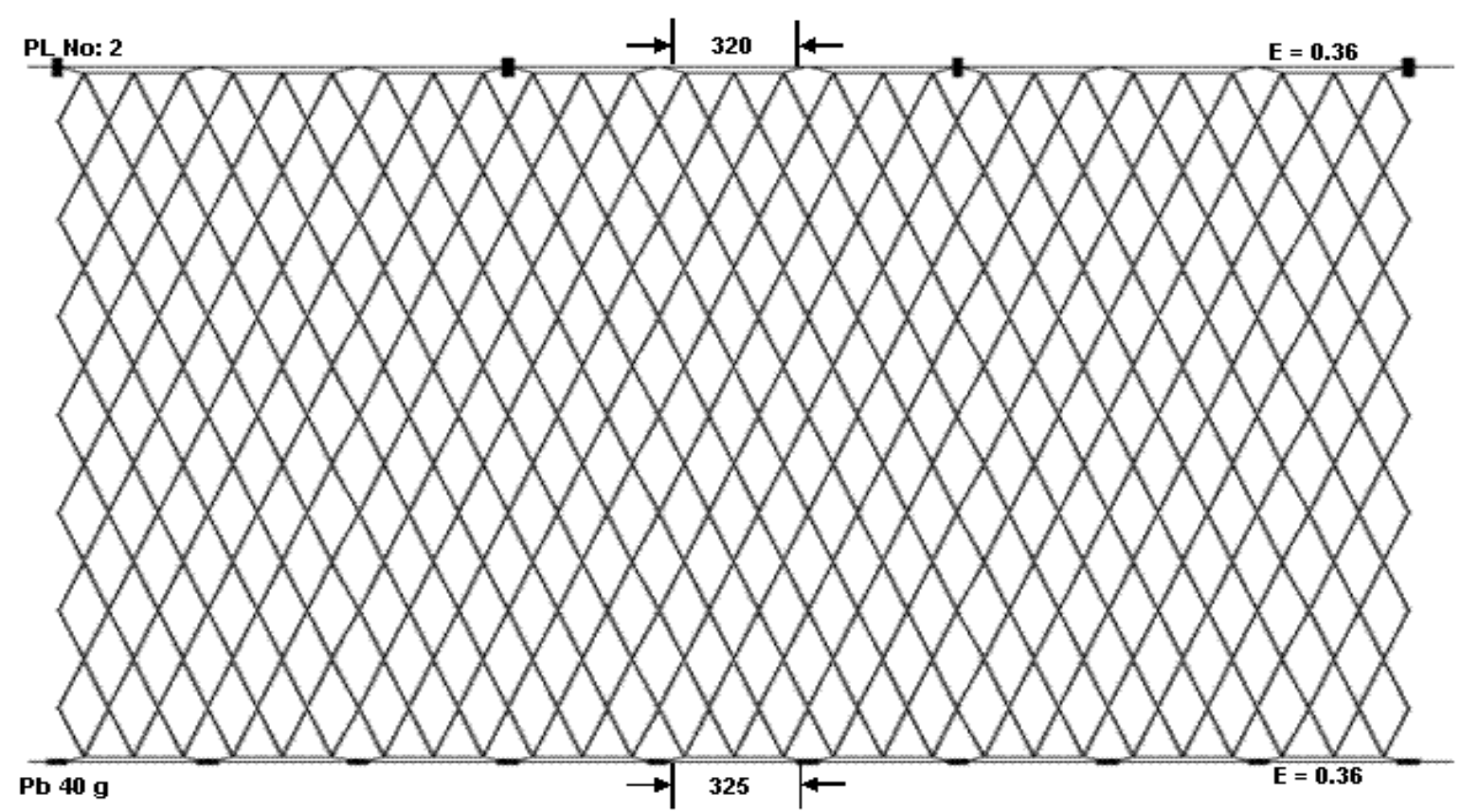

Şekil 2. Araştırmada kullanılan kalkan dip uzatma solungaç ağ planı.

Doluluk durumuna göre mideler boş, 1/4 oranında dolu (çok az dolu), 2/4 oranında dolu (yarı dolu), 3/4 oranında dolu (oldukça dolu) ve tam dolu olmak üzere 5 kategoriye ayrılmıştır (Aarefjord ve ark., 1995; Dolar ve ark., 2003; Ringelstein ve ark., 2006; Pusineri ve ark., 2007). Laboratuvarda her bir 
mide tartıldıktan sonra mideler bir küvet içerisine boşaltılmış ve boş mideler tekrar tartılmıştır. Buzları çözdürülmüş açılan mide içeriğindeki organizmalar $0.2 \mathrm{~mm}$ ağ göz açıklığındaki bir elekten geçirilerek yıkanmıştır. Mide içerikleri tanımlanabilen en küçük taksonomik seviyeye kadar belirlenmiştir. Mide içeriğinde saptanan besin grupları sindirilmiş olduğundan dolayı tartılmamıştır.

Mide içeriğinde rastlanılan balık türleri özellikle Tuset ve ark. (2008) tarafından belirtilen otolit şekillerinden ve arşivimizde bulunan Hamsi, İstavrit, Çaça, Tirsi, Mezgit, Barbun, Palamut, Kaya balığı otolitleri ile karşılaştırılarak tür tespiti yapılmıştır. Balıklarda 3 çift otolit (sagittae, lapilli ve asterisci) bulunduğu için her bir tip otolit sayılmış daha sonra en fazla bulunan otolit tipinin sayısı ikiye bölünerek o besin tipi için midedeki balık sayısı belirlenmiştir. Mide içeriği; yarı sindirilmiş, oldukça dolu ve tam dolu midelerdeki balıklardan görsel olarak ve balık omurlarından da faydalanılarak tespit edilmiştir.

Bulunuş frekansı yüzdeleri (\%FO), yunus bireylerinden yüzde kaçının belirli bir besin grubu ile beslendiğini verirken, besinsel organizmalarının sayısal yüzdeleri $(\% N)$ ise bir besin grubundaki miktarın mide içerisinde bulunan toplam besin miktarına yüzde olarak oranını verir (Hyslop, 1980). $\%$ ve $\% \mathrm{~N}$ aşağıdaki formüllere göre hesaplanmıştır.

$$
\begin{aligned}
& \% F O=\frac{n}{N s} x 100 \\
& \% N=\frac{n^{\prime}}{N p} x 100
\end{aligned}
$$

Burada,

$n$ bir besin grubunun bulunduğu yunus sayısını,

Ns mide içeriklerinde en az bir besin grubu bulunan toplam yunus sayısını,

$n$ ' bir besin grubunun toplam miktarını,

$N p$ bütün besin gruplarının toplam miktarıdır.

\section{Bulgular ve Tartışma}

Karaya vuran yunus türlerinin ölüm sonrası inceleme bulguları Tablo 1'de verilmiştir. Karaya vuran $P$. phocoena $(n=6)$ bireylerinin ölüm sebebinin kalkan dip uzatma solungaç ağlarına takıldıktan sonra öldüklerinden şüphelenilmektedir. Çünkü yunusların vücutlarında kalkan solungaç ağlarının izleri tespit edilmiştir. Diğer taraftan karaya vuran $D$. delphis $(n=4)$ bireylerden 1 tanesinin üst çenesinde teneke sapı, 1 tanesinin üzerinde ise kalkan solungaç ağı izleri tespit edilmiş, diğer 2 bireyin ise ölüm sebebi nekropsi yapılmadığından tespit edilememiştir (Şekil 3).
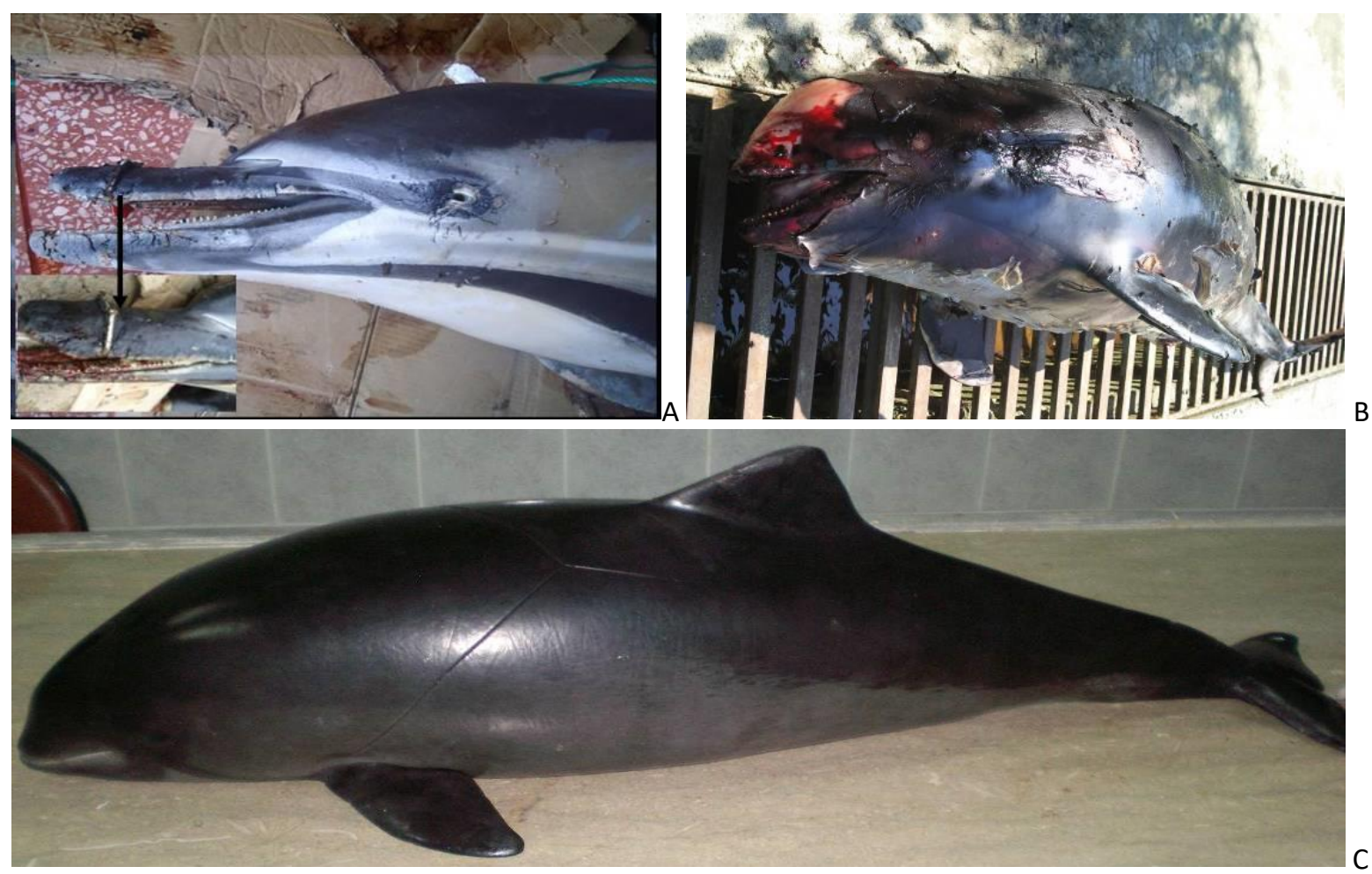

Şekil 3. Karaya vuran Tırtak bireylerden üst çenesinde teneke sapı (A), karaya vurmuş Mutur (B) ve üzerinde kalkan ağ ipi izleri olan Mutur (C). 
Tablo 1. Karaya vurmuş olarak tespit edilen Mutur ( $P$. phocoena) ve Tırtak ( $D$. delphis) türlerine ait ölüm sonrası bulgular.

\begin{tabular}{|c|c|c|c|c|c|c|c|}
\hline $\begin{array}{c}\text { Bulunma } \\
\text { Tarihi }\end{array}$ & $\begin{array}{l}\text { Karaya Vurma } \\
\text { Bölgesi }\end{array}$ & Tür & Cinsiyet & $\begin{array}{l}\text { Ağırlık } \\
\text { (kg) }\end{array}$ & $\begin{array}{l}\text { Boy } \\
(\mathrm{cm})\end{array}$ & $\begin{array}{c}\text { Yavru } \\
\text { Ağırlığı (kg) }\end{array}$ & $\begin{array}{l}\text { Muhtemel } \\
\text { Ölüm Sebebi }\end{array}$ \\
\hline 21.04.2010 & Fındıklı/Rize & $\begin{array}{l}P . \\
\text { phocoena }\end{array}$ & Dişi & 18.45 & 108.5 & & $\begin{array}{l}\text { Kalkan dip uzatma } \\
\text { solungaç ağı, boğulma }\end{array}$ \\
\hline 21.04.2010 & Fındıklı/Rize & $\begin{array}{l}P . \\
\text { phocoena }\end{array}$ & Erkek & 17.65 & 100.7 & & $\begin{array}{l}\text { Kalkan dip uzatma } \\
\text { solungaç ağı, boğulma }\end{array}$ \\
\hline 29.04.2010 & Merkez/Rize & phocoena & Erkek & 20.78 & 110.0 & & $\begin{array}{l}\text { Kalkan dip uzatma } \\
\text { solungaç ağı, boğulma }\end{array}$ \\
\hline 30.04 .2011 & Merkez/Rize & $\begin{array}{l}\text { P. } \\
\text { phocoena }\end{array}$ & $\begin{array}{l}\text { Hamile } \\
\text { dişi }\end{array}$ & 40.17 & 139.0 & 3.77 & $\begin{array}{l}\text { Kalkan dip uzatma } \\
\text { solungaç ağı, boğulma }\end{array}$ \\
\hline 30.04 .2011 & Merkez/Rize & $\begin{array}{l}P . \\
\text { phocoena }\end{array}$ & $\begin{array}{l}\text { Hamile } \\
\text { dişi }\end{array}$ & 39.67 & 142.0 & 1.59 & $\begin{array}{l}\text { Kalkan dip uzatma } \\
\text { solungaç ağı, boğulma }\end{array}$ \\
\hline 30.04 .2011 & Merkez/Rize & $\begin{array}{l}P . \\
\text { phocoena }\end{array}$ & Dişi & 18.70 & 105.5 & & $\begin{array}{l}\text { Kalkan dip uzatma } \\
\text { solungaç ağı, boğulma }\end{array}$ \\
\hline 05.04 .2010 & Merkez/Rize & D. delphis & $\begin{array}{l}\text { Hamile } \\
\text { dişi }\end{array}$ & 81.00 & 176.0 & 4.01 & $\begin{array}{l}\text { Belirlenemedi, } \\
\text { muhtemelen boğulma }\end{array}$ \\
\hline 29.04.2010 & Gündoğdu/Rize & D. delphis & Erkek & 78.30 & 194.7 & & $\begin{array}{l}\text { Belirlenemedi, } \\
\text { muhtemelen boğulma }\end{array}$ \\
\hline 14.05 .2010 & Merkez/Rize & D. delphis & Erkek & & 186.5 & & Belirlenemedi \\
\hline 30.04 .2011 & Merkez/Rize & D. delphis & Erkek & 40.47 & 155.0 & & $\begin{array}{l}\text { Kalkan dip uzatma } \\
\text { solungaç ağı, boğulma }\end{array}$ \\
\hline
\end{tabular}

Kazaen yakalanan ve karaya vurmuş olarak elde edilen yunuslardan $16 P$. phocoena türünün (Şubat 1, Nisan 7 ve Mayıs 8 birey) nekropsi sonucunda karnında yavru olduğu belirlenmiştir. 13 bireyden elde edilen yavruların ağırlıkları tartılmıştır. Doğmamış yavru ağırlıkları ise 1088 -

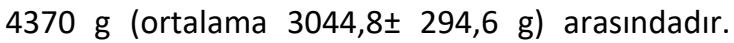
(doğmamış 13 yavru ağılıkları: 4344 g, 1088 g, 2194 g, 2346 g, 3770 g, 1590 g, 4260 g, 2800 g, 4370 g, 2910 g, 2910, 3960 g, 3040g).

Karaya vuran $D$. delphis bireylerinden sadece 1 'inin (Nisan) yavrulu olduğu belirlenmiştir. Verilerimize göre $P$. phocoena türünün Şubat ve Mayıs ayları arasında ergin bireylerin karnında yavru olduğu yani bu dönemde gebe olduğu saptanmıştır. Total boyları (TL) 85,6 cm ile $142 \mathrm{~cm}$ arasında (ortalama $=116.0 \pm 2.4 \mathrm{~cm}$ ) olan 52 adet (Şubatta 1 ,
Nisanda 37 ve Mayıs 14 yunus) Mutur dan 35 tanesinin midesi boş bulunmuştur. Bu verilere göre incelenen bireylerin biri hariç diğerlerinin ilkbahar mevsiminde istem dışı olarak yakalandığı tespit edilmiştir. Yani beslenme bulguları ilkbahar mevsimini yansıtmaktadır. Incelenen Mutur bireylerinin midelerinin büyük çoğunluğunun boş olduğu (\%67.3 boş), \%15.4 az dolu, \%7.7 yarı dolu, $\% 5.8$ oldukça dolu ve çok az bir kısmının (\%3.8) ise midesinin tam dolu olduğu belirlenmiştir.

Genel mide içeriği analiz sonuçlarına göre, Karadeniz'de Mutur türünün sayısal miktar olarak başlıca Hamsi ( $\% \mathrm{~N}=86.12$ ) ve Mezgit (\% $\mathrm{N}=11.63$ ) ile beslendiği belirlenmiştir (Tablo 2). Bulunuş frekansı yüzdesine (\%FO) göre ise Mutur bireylerinin \%63.08'inin Hamsi ve \%24.61'inin Mezgit balıkları ile beslendiği saptanmıştır.

Tablo 2. Karadeniz' de 52 adet Mutur ( $P$. phocoena) türünün mide içeriğinde tespit edilen besinsel organizmaların sayısal miktarı (\%N) ve bulunuş frekansı (\% FO).

\begin{tabular}{|c|c|c|c|}
\hline \multicolumn{2}{|c|}{ Besinsel organizmalar } & \multirow{2}{*}{$\begin{array}{c}\text { \%FO } \\
63.08\end{array}$} & \multirow{2}{*}{$\frac{\mathbf{\% N}}{86.12}$} \\
\hline Hamsi & Engraulis encrasicolus & & \\
\hline İstavrit & Trachurus sp. & 10.77 & 1.84 \\
\hline Mezgit & Merlangius merlangus euxinus & 24.61 & 11.63 \\
\hline \multirow[t]{2}{*}{ Denizatı } & Hippocampus hippocampus & 1.54 & 0.41 \\
\hline & & 100 & 100 \\
\hline
\end{tabular}

Total boyları (TL) $122.0 \mathrm{~cm}$ ile $194.7 \mathrm{~cm}$ arasında (ortalama $=167.6 \pm \mathrm{cm}$ ) olan 6 adet (Nisanda 3, Mayıs 1 ve Haziranda 2) Tırtak bireyinin mide içerikleri incelenmiştir. Incelenen midelerin 2 tanesi boş, 1 tanesi çok az dolu ve 3 tanesi ise dolu olarak saptanmıştır. Genel mide içeriği analiz sonuçlarına göre, Karadeniz'de Tırtak türünün sayısal miktar olarak başlıca Mezgit (\%N = 86.85) balığıyla beslendiği belirlenmiştir. Bulunuş frekansı yüzdesine göre (\%FO) ise Tırtak bireylerinin \%42.86'sinin Hamsi ve i̇stavrit balıkları oluşturmuştur (Tablo 3, Şekil 4). 
Tablo 3. Karadeniz'de 6 adet Tırtak (Delphinus delphis) türünün mide içeriğinde tespit edilen besinsel organizmaların sayısal miktarı (\%N) ve bulunuş frekansı (\% FO).

\begin{tabular}{|c|c|c|c|}
\hline \multicolumn{2}{|c|}{ Besinsel organizmalar } & \multirow{2}{*}{$\frac{\% \text { FO }}{42.86}$} & \multirow{2}{*}{$\begin{array}{r}\mathbf{\% N} \\
7.76\end{array}$} \\
\hline Hamsi & Engraulis encrasicolus & & \\
\hline İstavrit & Trachurus sp. & 42.86 & 5.39 \\
\hline Mezgit & Merlangius merlangus euxinus & 14.28 & 86.85 \\
\hline \multirow[t]{2}{*}{ Denizatı } & Hippocampus hippocampus & 0 & 0 \\
\hline & & 100 & 100 \\
\hline
\end{tabular}
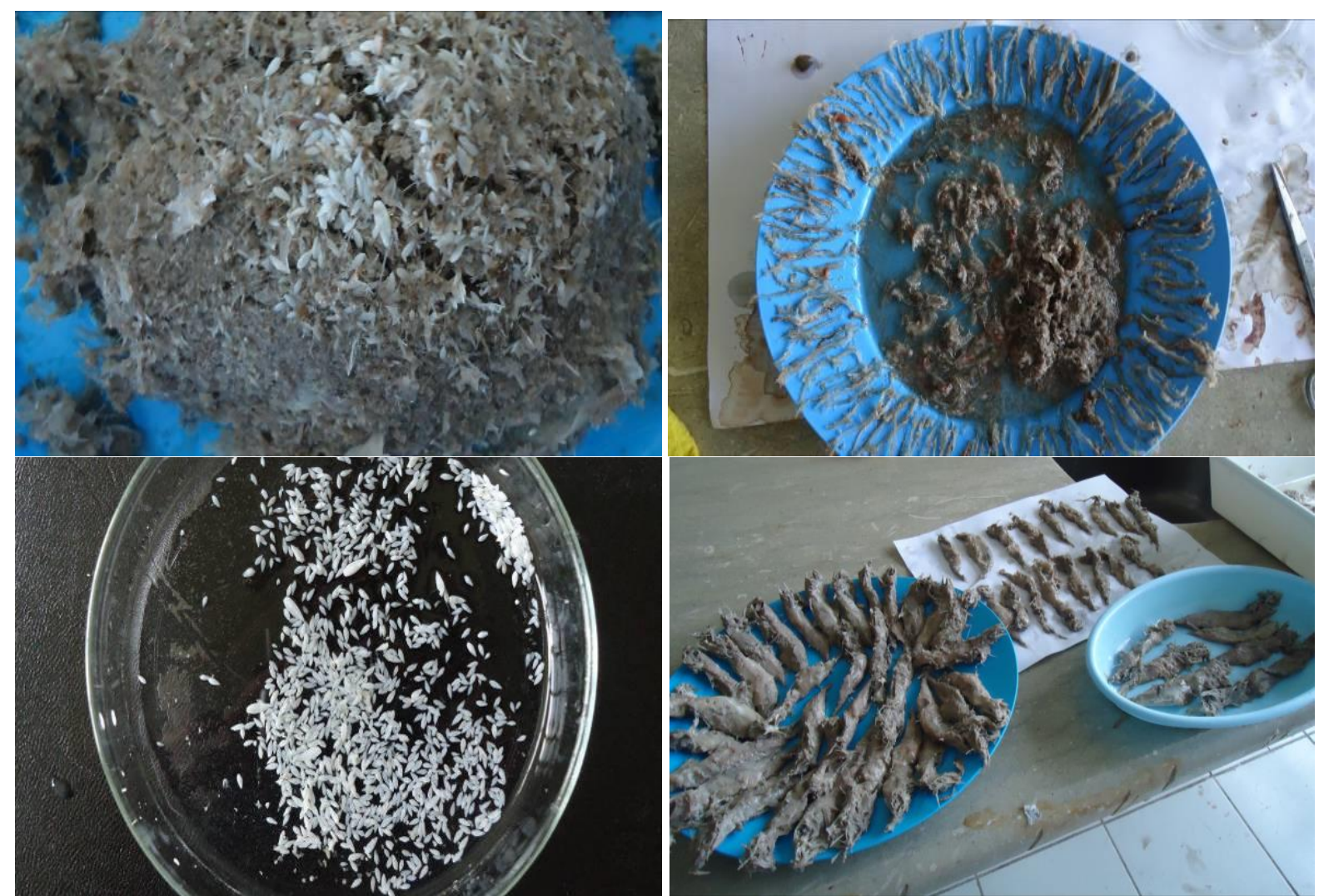

Şekil 4. Tırtak türünün mide içeriği (Hamsi, İstavrit, Mezgit omurları ve otolitleri).

\section{Sonuç ve Öneriler}

Karaya vuran yunuslar üzerinde yapılan incelemelerde yunusların çoğunluğun kalkan dip uzatma solungaç ağlarıyla yapılan avcılık neticesinde ağlara takılarak boğulduğu ve daha sonra ağlardan çıkarılan yunuslar denize bırakılması neticesinde dalga ve rüzgâr gibi etkenlerden dolayı sahile sürüklendikleri tahmin edilmektedir (Balıkçılarla yapılan kişisel görüşmelerde de ağlarına yakalanan yunusları denize attıkları belirlenmiştir). Karaya vuran yunuslar üzerinde yapılan incelemelerde yunusların üzerinde kalkan ağ iplerinin izi tespit edilmiştir. Ayrıca bir Tırtak türünün ise çenesinde teneke sapının saplanmış olduğu ve bunun neticesinde ölmüş olabileceğinden şüphelenilmiştir. Karaya vuran yunuslar üzerinden yapılan incelemeler neticesinde, yunusların ölüm sebeplerinin başında avcılık sırasında ağlara kazara takılıp boğulmaları ve deniz kirliliğinin etkili olduğu düşünülmektedir.
Fundy Körfezinde $P$. phocoena türü Haziran sonlarına doğru gebe kalmakta, gebelik yaklaşık 10.6 ay sürmekte ve doğum Mayıs ayı ortalarında gerçekleşmektedir (Read, 1990). Franse (2005), ise Mutur türünün gebelik döneminin 10.5 ay, doğumunun ise Mayıs ve Ağustos ayları arasında gerçekleştiğini bildirmiştir. Diğer taraftan, Gol'din (2004), Mutur türünün Karadeniz'de üreme zamanının Nisan ve Ağustos arasında olduğunu bildirmiştir. Kuzey Denizi'nde (İskoçya, Aberdeenshire) yeni doğmuş ve juvenil bireyler Haziran-Eylül arasında kaydedilmiştir. Bu çalışmada ise $P$. phocoena türünün diseksiyon sonucunda karnında yavruları tamamen gelişmiş doğum öncesi safhada olan bireylere Şubat, Nisan ve Mayıs aylarında rastlanılmıştır. Mayıs ayından sonra elde edilen yunus bireylerinin hiç birinin karnında yavru tespit edilememiştir. $D$. delphis türünün sadece 1 bireyinin (Nisan) yavrulu olduğu belirlenmiştir. 
Bu sonuçlara göre güney doğu Karadeniz'de Mutur türünün Şubat ve Mayıs arasında doğum gerçekleştirdiği söylenebilir. Ayrıca yunusların hamile iken çiftleşmedikleri ve doğum sonrasında çiftleştikleri bildirilmiştir (Read, 1990). Mutur türünün gebelik süresinin yaklaşık 11 ay olduğu düşünüldüğünde araştırma bölgesinde en erken Şubat/Mart gibi doğum yapmış bir Muturun doğumdan sonra en erken Nisan/Mayıs aylarında çiftleşmeye başladığı sonucu çıkarılabilir.
Birkun, (2002) yaptığı derleme çalışmasında; Karadeniz'de yaşayan yunus türlerinin 1950'li yıllardan önce mide içeriğinde 30 civarında balık üzerinden beslendiğini, Muturun; Hamsi, Çaça, Mezgit ve Kaya balıklarını (Gobiidae) birincil olarak, Kefal türleri, Barbun balığı, Tirsi, Pisi, Dil, İzmarit ve Gümüş balıklarını ise ikincil olarak tercih ettiğini rapor etmiştir (Tablo 4).

Tablo 4. Yunusların Karadeniz'de tükettikleri hedef balık türleri, ticari balıklar ve tüketim öncelikleri, P: birincil, S: ikincil, U: hedef olmayan türler (Birkun, 2002'den).

\begin{tabular}{|c|c|c|c|c|}
\hline \multirow[b]{2}{*}{ BALIK TÜRÜ } & \multicolumn{4}{|c|}{ TÜKETICI } \\
\hline & $\begin{array}{c}\text { Tırtak } \\
\text { D. delphis } \\
\end{array}$ & $\begin{array}{c}\text { Afalina } \\
\text { T. truncatus }\end{array}$ & $\begin{array}{c}\text { Mutur } \\
\text { P. phocoena }\end{array}$ & Balıkçılık \\
\hline Hamsi, Engraulis encrasicolus ponticus & $\mathrm{P}$ & $\mathrm{S}$ & $P, S$ & $P$ \\
\hline Çaça, Sprattus sprattus phalaericus & $P$ & $U$ & $\mathrm{P}$ & $\mathrm{P}$ \\
\hline Mezgit, Merlangius merlangus euxinus & $S$ & $P, S$ & $P, S$ & $\mathrm{~S}$ \\
\hline Syngnathidae & $\mathrm{P}, \mathrm{S}$ & $U$ & $U$ & $U$ \\
\hline Kalkan, Psetta maeotica & $U$ & $P$ & $U$ & $P$ \\
\hline Vatoz, Raja clavata & $U$ & $P, S$ & $U$ & $\mathrm{~S}$ \\
\hline Kefal, Liza spp. & $S$ & $P, S$ & $S$ & $P$ \\
\hline Has kefal, Mugil cephalus & $U$ & $P, S$ & $U$ & $P$ \\
\hline Rus kefali, Mugil soiuy & $U$ & $\mathrm{P}$ & $\mathrm{S}$ & $\mathrm{P}$ \\
\hline Kaya balığı, Gobiidae & $U$ & $U$ & $P$ & $\mathrm{~S}$ \\
\hline Barbun, Mullus barbatus ponticus & $S$ & $S$ & $\mathrm{~S}$ & $P$ \\
\hline Palamut, Sarda sarda & $S$ & S & $U$ & $\mathrm{P}$ \\
\hline Tirsi, Alosa spp. & $S$ & $U$ & $\mathrm{~S}$ & $P$ \\
\hline Levrek, Lucioperca lucioperca & $U$ & $\mathrm{~S}$ & $\mathrm{~S}$ & $U$ \\
\hline Lüfer, Pomatomus saltator & $S$ & $\mathrm{U}$ & $U$ & $\mathrm{P}$ \\
\hline İstavrit, Trachurus spp. & $S$ & $U$ & $U$ & $\mathrm{P}$ \\
\hline Zargana, Belone belone euxini & $S$ & $U$ & $U$ & $\mathrm{~S}$ \\
\hline Uskumru, Scomber scombrus & $S$ & $U$ & $U$ & $P$ \\
\hline Lapin, Labridae & $S$ & $U$ & $U$ & $U$ \\
\hline Horozbina, Blenniidae & $S$ & $U$ & $U$ & $U$ \\
\hline İskorpit, Scorpaena porcus & $U$ & $\mathrm{~S}$ & $U$ & $U$ \\
\hline Gümüş balığı, Atherina sp. & $U$ & $U$ & $\mathrm{~S}$ & $U$ \\
\hline Pisi balığı, Platichthys flesus luscus & $U$ & $U$ & $\mathrm{~S}$ & $\mathrm{~S}$ \\
\hline Dil balığı, Solea nasuta & $U$ & $U$ & $\mathrm{~S}$ & $U$ \\
\hline İzmarit balığı, Spicara smaris & $\mathrm{U}$ & U & $\mathrm{S}$ & U \\
\hline
\end{tabular}

Türkiye'nin Karadeniz sularında NisanHaziran 2002 ve 2003 yıllarında 42 Mutur türünün mide içeriğinin incelendiği bir çalışmada, incelenen bireylerin midesinde 3304 otolit tespit edilmiş, 1935 otolit ise tanımlanamamıştır (Tonay ve ark., 2007). Söz konusu çalışmada Mutur türünün midesinde Çaça, Mezgit, Dil balığı, Kaya balıkları, Bakalyaro, Hamsi ve Barbun balıkları ile kabuklu su ürünleri, alg parçaları, midye, çamur ve plastik materyaller tespit edilmiştir. Aynı çalışmada Mutur türünün mide içeriğinin \%64.1 oranında Çaça ve \%23.6 oranında Mezgit balıklarından oluştuğu rapor edilmiş olup incelenen midelerin ne kadarının dolu olduğu belirtilmemiştir. Bu çalışmada bir birey hariç ilkbahar aylarında elde edilen (Şubatta 1, Nisanda
37 ve Mayıs 14) 52 adet Mutur türünün mide içerikleri incelenmiştir. Muturun midesinde Hamsi, İstavrit, Mezgit ve Denizatı tespit edilmiştir. Incelenen Mutur bireylerinin midelerinin \%67'sinin boş olduğu (35 birey), \%6'sının ise (2 birey) midesinin tam dolu olduğu belirlenmiştir. Diğer taraftan incelenen mide verilerine göre, araştırma bölgesinde Mutur başlıca Hamsi (\% N= 86; \%FO= $\% 63)$, Mezgit (\% N=12; \% FO= \%25) ve İstavrit (\% N= $2 ; \% \mathrm{FO}=\% 11$ ) balıkları ile beslenmiştir. Elde edilen sonuçlar, Karadeniz'de Tonay ve ark. (2007) tarafından elde edilen sonuçlarla kıyaslandığında, Muturun beslenme alışkanlığı bakımından Mezgit ile beslenmesinin benzer olduğu, ancak batı Karadeniz'de Çaça balığının yerine doğu 
Karadeniz'de Hamsi ve İstavrit ikame etmiştir. Bu durumun mümkün olduğu söylenebilir. Çünkü, Muturun besin tercihi bölge, mevsim ve yıllar arasında değişiklik gösterebilmektedir (Aarefjord ve ark., 1995; Santos ve Pierce, 2003).

Birkun (2002), 1960 öncesine kadar Karadeniz'de Tırtak türünün birincil olarak Hamsi ve Çaça, ikincil olarak ise Mezgit, Kefal türleri, Barbun, Palamut, Tirsi, Lüfer, İstavrit, Zargana, Uskumru ile Labridae ve Blenniidae familyasına ait balıkları tercih ettiğini rapor etmiştir. Yunus türlerinin besin tercihinin yıllar içerisinde, mevsim ve coğrafik varyasyonlara göre değişebileceği düşünüldüğünde (Aarefjord ve ark., 1995; Santos ve Pierce, 2003) bizim verilerimize göre Tırtak türünün beslendiği balık tür çeşitliliğinin azaldığı ve özellikle pelajik balıklardan Hamsi ve İstavrit balıklarıyla beslendiği düşünülmektedir.

\section{Kaynaklar}

Aarefjord, H., Bjørge, A., Kinze, C.C., Lindstedt, I. 1995. Diet of the harbour porpoises (Phocoena phocoena) in Scandinavian waters. In special issue, 16, Biology of phocoenids, A. Bjørge and G.P. Donovan (eds). Cambridge: International Whaling Commission, 211-222.

ACCOBAMS, 2007. Report of the Third Meeting of the Contracting Parties to ACCOBAMS, $350 \mathrm{pp}$.

Birkun, A.Jr. 2002. Interactions between Cetaceans and Fisheries in the Black Sea, In: G, Notarbartolo di Sciara (Ed,), Cetaceans of the Mediterranean and Black Seas: State of Knowledge and Conservation Strategies. A report to the ACCOBAMS Secretariat, Monaco, February 2002. Section 10, $11 \mathrm{p}$.

Dolar, M.L.L., Walker, W.A., Kooyman, G.L., Perin, W.F. 2003. Comparative Feeding Ecology of Spinner Dolphins (Stenella longirostris) and Fraser's Dolphins (Lagenodelphis hosei) in the Sulu Sea, Marine Mammal Science, 19(1): 119.

Duignan, P.J., Gibbs, N.J., Jones, G.W. 2003. Autopsy of Cetaceans Incidentally Caught in Fishing Operations 1997/98, 1999/2000, and 2000/01, DOC SCIENCE INTERNAL SERIES 119. Published by Department of Conservation P.O. Box 10-420 Wellington, New Zealand, 31 p.

Franse, R. 2005. Effectiveness of Acoustic Deterrent Devices (Pingers), Universiteit Leiden Centrum voor Milieuwetenschappen Leiden Juli 2005, $33 \mathrm{p}$.

Gol'din, P.E. 2004. Growth and body size of the harbour porpoise Phocoena phocoena (Cetacea, Phocoenidae) in the Sea of Azov and the Black Sea. Vestnik Zoologii, 38(4): 59-73.
Hyslop, E.J. 1980. Stomach contents analysis a review of methods and their application. Journal of Fish Biology, 17: 411-429.

Jefferson, T.A., Leatherwood, S., Webber, M.A. 1993. FAO Species Identification Guide. Marine Mammals of the World, 320p.

Öztürk, B., Öztürk, A.A., Dede, A. 1999. Cetacean Bycatch in the Western Coast of the Turkish Black Sea in 1993-1997. P, 134 [in: P,G,H, Evans, J, Cruz and J,A, Raga (Eds,), European research on Cetaceans - 13 (Proc,13th Annual Conf, European Cetacean Society, Valencia, Spain, 5-8 Apr1999), ECS, Valencia, 484 p].

Öztürk, B., Aktan, Y., Topaloğlu, B., Keskin, Ç., Karakulak, S., Öztürk, A.A., Dede, A., Tükozan, O. 2004. Marine Life of Turkey, in the Aegean and Mediterranean Seas. Turkish Marin Research Foundation (TÜDAV), Uniprint Basım San. ve Tic. A.Ş., İstanbul, 200 p.

Pusineri, C., Magnin, V., Meynier, L., Spitz, J., Hassani, S., Ridoux, V. 2007. Food and feeding ecology of the common dolphin (Delphinus delphis) in the oceanic Northeast Atlantic and comparison with its diet in neritic areas. Marine Mammal Science, 23(1): 30-47.

Read, A.J. 1990. Reproductive seasonality in harbour porpoises, Phocoena phocoena, from the Bay of Fundy. Canadian Journal of Zoology, 68(2): 284-288.

Read, A.J., Drinker, P., Northridge, S. 2004. Bycatches of marine mammals in U.S. and global fisheries. Conservation Biology, 20(1): 163169.

Ringelstein, J., Pusineri, C., Hassani, O.S., Meynier, L., Nicolas, R., Ridoux, V. 2006. Food and feeding ecology of the striped dolphin, Stenella coeruleoalba, in the oceanic waters of the north-east Atlantic. Journal of the Marine Biological Association of the United Kingdom, 86: 909-918.

Santos, M.B., Pierce, G.J. 2003. The diet of harbour porpoises (Phocoena phocoena) in the Northest Atlantic. Oceanogarhy and Marine Biology, 41: 355-390.

Tonay, A.M., Dede, A., Öztürk, A.A., Öztürk, B. 2007. Stomach content of harbour porpoises (Phocoena phocoena) from the Turkish Western Black Sea in spring and early summer. Rapp. Comm. Int. Mer. Médit., 37.

Tuset, V.M., Lombarte, A., Assis, C.A. 2008. Otolith Atlas for Western Mediterranean, North and Central Eastern Atlantic. Scientia Marina, 72(1): 7-198.

Zaitsev, Y.P., Mamaev, V. 1997. Marine Biological Diversity in the Black Sea: A Study of Change and Decline. GEF Black Sea Environment Progress. U.N. Publications, New York. 